\title{
REMOÇÃO TARDIA DE TERCEIRO MOLAR SUPERIOR DESLOCADO PARA A FOSSA INFRATEMPORAL
}

Bruno Tochetto PRIMO, Rafaela Scariot de MORAES, Diego José STRINGHINI, Leandro Eduardo KLUPPEL, Delson João COSTA

A remoção de terceiros molares superiores impactados é um procedimento comumente realizado pelo cirurgião dentista e geralmente associado com pouca morbidade e complicações. Uma complicação raramente reportada é o deslocamento do dente para a fossa infratemporal. Diferentes formas de manejo cirúrgico são encontradas na literatura. $O$ tratamento recomendado inclui a remoção cirúrgica imediata se possível, o acompanhamento ou a remoção em um segundo momento cirúrgico. O objetivo do trabalho é relatar a remoção de um dente da fossa infratemporal. Paciente do gênero masculino, 14 anos foi encaminhado ao Serviço de Cirurgia e Traumatologia Buco-maxilo-faciais para remoção de terceiros molares. Durante a remoção do terceiro molar superior direito (18) houve 0 deslocamento do mesmo para a fossa infratemporal. No momento o paciente e o responsável foram avisados da situação. Optou-se pela remoção do dente em um segundo momento. Após quatro meses, o procedimento cirúrgico foi realizado sob anestesia local através de incisão com eletrocautério sobre o ponto de palpação dentário que estava localizado em fundo de vestíbulo. $O$ dente encontrava-se envolto por fibras musculares que foram dissecadas permitindo a remoção do dente. O paciente encontra-se sem queixas funcionais. Em nova radiografia panorâmica foi possivel observar a completa remoção do dente.

Palavras-Chave: Dente Incluso; Complicações; Terceiro Molar 